\title{
Research Paper: Prevalence of Neuromuscular Deficien- cies Associated With Non-Contact Anterior Cruciate Ligament Injury in Healthy Collegiate Student-Athletes
}

\author{
Hemen Mohammadi $^{1 *}$ (D) , Saeed Ghaeeni ${ }^{1}$
}

1. Department of Physical Education and Sports Sciences, Faculty of Humanities and Social Sciences, University of Kurdistan, Sanandaj, Iran

\begin{tabular}{|l|l|}
\hline $\begin{array}{l}\text { Use your device toscan } \\
\text { and read the articleonline }\end{array}$ & $\begin{array}{l}\text { Crtation Mohammadi H, Ghaeeni S. Prevalence of Neuromuscular Deficiencies Associated With Non-Contact Anterior } \\
\text { Cruciate Ligament Injury in Healthy Collegiate Student-Athletes. Physical Treatments. 2019; 9(4):193-202. http://dx.doi. } \\
\text { org/10.32598/ptj.9.4.193 }\end{array}$ \\
doj http://dx.doi.org/10.32598/ptj.9.4.193
\end{tabular}

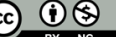

Article info:

Received: 12 Mar 2019

Accepted: 05 Aug 2019

Available Online: 01 Oct 2019
Keywords:

Jumping, Anterior Cruciate Ligament (ACL), Neuromuscular disorders, Knee, Sport injury prevention

\begin{abstract}
A B S T RA C T
Purpose: Identifying lower extremity defects during high impact activity, such as landing, especially in young athletes who play team sports, could help to prevent non-contact lower extremity injuries. The Tuck Jump Assessment (TJA) is a screening instrument designed to recognize neuromuscular deficits related to Anterior Cruciate Ligament (ACL) injury. The current study investigated the prevalence rate of neuromuscular deficits during tuck jump in female and male physical education and sports sciences collegiate students.
\end{abstract}

Methods: The study subjects included all undergraduate students of physical education and sports science at the University of Kurdistan in 2018-2019 academic year (male/female $=55-77$, Mean \pm SD age: $21.3 \pm 1.7$ y, weight: $63.4 \pm 12.3 \mathrm{~kg}$, height: $169.4 \pm 9.5 \mathrm{~cm}$, body mass index: $21.97 \pm 2.94 \mathrm{~kg} /$ $\mathrm{m} 2$, and sports experience: $4.95 \pm 3.38 \mathrm{y}$ ). All study subjects conducted the TJA, which consisted of continuous maximal height tuck jumps for 10 seconds. Tuck jump performance was recorded by two cameras in sagittal and frontal planes and was evaluated using the Kinovea software. The performance was scored across 10 criteria using the modified scale (0-2).

Results: One-Way Analysis of Variance (ANOVA) results revealed a significant difference between the tuck jump scores in male and female athletes $(\mathrm{P}<0.01)$. The difference between male and female athletes was not significant in neuromuscular fatigue and quadriceps dominance; in both groups, the prevalence of these defects was $<15 \%$. However, there was a significant difference between the ligament dominance, trunk dominance, and leg dominance of male and female athletes $(\mathrm{P}<0.01)$. The prevalence of leg dominance in males $(65.5 \%: 49.1 \%$ grade $1,16.4 \%$ grade 2$)$ was higher than that of the females (45.5\%: $40.30 \%$ grade $1,5.2 \%$ grade 2$)$. But the prevalence of ligament dominance in females (81.8\%: $51.9 \%$ grade $1,29.9 \%$ grade 2 ) was higher than that of the males (40\%: $34.5 \%$ grade $1,5.5 \%$ grade 2$)$. Besides, the prevalence of trunk dominance in females $(72.7 \%: 57.1 \%$ grade $1,15.6 \%$ grade 2$)$ was higher than that of the males $(26.3 \%: 25.5 \%$ grade $1,1.8 \%$ grade 2$)$.

Conclusion: The mean score of incidence of the ligament dominance, trunk dominance, and leg dominance was $>50 \%$ in the study subjects. Thus, it is recommended that preventive exercise programs emphasize on the correction of these defects. The correction of leg dominance deficiency is a priority among males; however, the correction of ligament dominance and trunk dominance is the priority among females.

\footnotetext{
* Corresponding Author:

Hemen Mohammadi, PhD.

Address: Department of Physical Education, Faculty of Humanities and Social Sciences, University of Kurdistan, Sanandaj, Iran. Phone: +98 (914) 4880973

E-mail: hemn.m.64@gmail.com
} 


\section{Highlights}

- More than $50 \%$ of physical education students have ligament dominance, leg dominance, and trunk dominance.

- Recommended that specializing in the prevention of ACL injuries in physical education students focus on correction ligament dominance, leg dominance, and trunk dominance.

- In female, the correction ligament dominance and trunk dominance are periority. But in male, the correction leg dominance is periorety.

\section{Plain Language Summary}

The purpose of this study was to investigate the prevalence rate of neuromuscular deficits during tuck jump in female and male physical education and sports sciences University of Kurdistan students in 2018-2019 academic year. After Tuck jump test which recorded by two cameras, the performance evaluated using the Kinovea software. The implicor cations of this study might suggest that personal trainers, coaches, and basketball players employ this rective exercise program to improve knee kinematic during drop vertical jump and enhance athletes' performance. The mean score of incidence of the ligament dominance, trunk dominance, and leg dominance was $>50 \%$. Therefore, it is recommended that preventive exercise programs emphasize on the correction of these defects. The correction of leg dominance deficiency is a priority among males; however, the correction of ligament dominance and trunk dominance is the priority among females.

\section{Introduction}

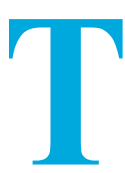

he prevalence of sports injuries in college athletes (from 2009-2010 to 2014-2015) in 25 sports suggested that the most common injured body part is the knee (32.9\%). Moreover, in indoor sports, like women's volleyball, $>50 \%$ of the injuries occur in the knee joint [1]. Additionally, the most common injury is sprains (32.9\%); in indoor sports, like women's soccer, $>50 \%$ of the injuries is sprain [1]. Anterior Cruciate Ligament (ACL) tear is the most frequent severe injury in women's lacrosse $(28.1 \%)$, women's soccer $(25.9 \%)$, women's volleyball (25.7\%), women's basketball (20.8\%), men's lacrosse (17.4\%), softball (14.8\%), men's football (14.0\%), women's gymnastics (13.9\%), and men's basketball $(12.0 \%)$ [1]. The proportion of severe injuries is higher in women, compared to men for overuse and noncontact mechanisms [1]. Investigating gender differences in the incidence of ACL, Medial Collateral Ligament (MCL), and meniscal injuries in collegiate and high school sports (from 2009-2010 to 2013-2014) revealed that ACL injury in female athletes is higher than that of male athletes at both levels; however, there was no distinct gender disparity in MCL and meniscal injuries [2]. Furthermore, ACL injuries had the highest number of cases treated with surgery with high treatment costs, the loss of sports participation, and the creation of secondary injuries, including osteoarthritis [3].
For example, the incremental cost-effectiveness ratio of ACL reconstruction, compared with physical therapy, was $\$ 22702$ per quality-adjusted life-years in competitive athletes [4]. Besides, at least two-thirds of ACL sprains occur during noncontact situations and their peak incidence is between 19 and 25 years of age [3]. Therefore, the present study investigated the prevalence of neuromuscular deficiencies associated with non-contact ACL injury in the female and male athletes aged 18 to 25 years. Probably, there is a multi-factorial mechanism behind this gender differences in ACL injury incidence. However, among the intrinsic risk factors for ACL injury (anatomic, hormonal, and neuromuscular abnormalities), only the neuromuscular control is modifiable [5]. Neuromuscular dysfunction increases the load on the lower extremities joints during sports activities; therefore, it is the leading risk factor for noncontact ACL injuries [5]. Numerous studies have investigated the neuromuscular deficiencies, mechanisms, and the impact of intervention exercises on ACL injury [5-7].

Conventionally, 3-dimensional motion capture during high impact activities, such as directional changes and landing is used to assess kinematic variables and to identify knee and ACL injury risks [8, 9]. However, using such analysis for assessments is time consuming and costly; thus, it is impractical in most clinical settings. The ability to maintain dynamic knee stability during landing and jumping generates from sufficient 
neuromuscular control [9]. Various measures have been created to test for neuromuscular deficiencies correlated with an increased ACL injury rate. There are several jumping and landing 2-dimensional tests, including the Landing Error Scoring System (LESS) [10], the Drop Vertical Jump (DVJ) test [11] and the Tuck Jump Assessment (TJA) [12]. The LESS and DVJ inventories only require three jumps; however, in the TJA, athletes must perform consecutive jumps for 10 seconds. The TJA is a full effort plyometric jump task and may better reflect sport-specific jumping and landing activities. Therefore, the TJA might highlight unobservable landing defects in three non-consecutive jumps [10-12]. Because TJA is very practical and efficiently performed, the researchers can use it to screening neuromuscular imbalances in athletes [12].

Moreover, using a double-leg jump task in TJA may allow to detect side-to-side asymmetries. In this study, male and female youth athletes were assessed applying the modified TJA [13]. Changing the scoring system from the original scale $(0-1)$ to a modified scale $(0-2)$ results in providing further objective information about ACL injury risk in athletes [13]. Vanmeerhaeghe et al. reported good to excellent intra- and inter-rater reliability for most items of the modified TJA [13].

Hewett et al. in a video analysis on the athlete injury risk during tuck jump identified 4 neuromuscular imbalances as the underlying mechanisms of non-contact ACL injuries [5]. Jumps and landings during the TJA were analyzed with 10 items, used to assess these 4 neuromuscular imbalances (ligament, quadriceps, leg, and trunk dominance) [5]. Most of the deviations from the desired movement pattern were caused by impaired neuromuscular control strategies. Six different neuromuscular deficits may contribute to lower extremity and especially ACL pathomechanics during high impact activities, such as jumping and landing [14]. These 6 neuromuscular deficits include the following: 1. Dynamic valgus or ligament dominance (increased reliance on the frontal plate control relative to the sagittal plane); 2. Quadriceps dominance (lower contributions of hamstring muscles resulting in quadriceps dominant strategy to stabilize the knee joint); 3. Leg dominance (greater strength, balance, and coordination in the dominant leg); 4. Trunk dominance (decreased stability and proprioception of the trunk); 5. Neuromuscular fatigue; and 6. feed-forward mechanisms deficits $[13,15]$. Accordingly, the present study investigated the prevalence of neuromuscular deficiencies during TJA (ligament dominance, quadriceps dominance, leg dominance, trunk dominance, and neu- romuscular fatigue) in female and male physical education and sports science collegiate students.

\section{Materials and Methods}

All female and male undergraduate students of Physical Education and Sports Science faculty at the University of Kurdistan in 2018-2019 academic year comprised the study population. The students $(\mathrm{N}=132)$ who met the inclusion criteria were selected as study subjects (77 female and 55 male). Inclusion criteria consisted of being undergraduate students of Physical Education and Sports Science at the University of Kurdistan in 20182019 academic year, being aged 18-25 year, conducting $\geq 3$ sessions of exercise per week, having normal Body Mass Index (BMI). Exclusion criteria were having a history of surgery in the trunk and ACL injury or severe lower extremity injury during the past year, chronic trunk and lower extremity injuries (e.g. chronic ankle instability), having any injury (overuse or acute) at the time of testing, and participation in ACL injury prevention exercise programs. All study participants received an explanation regarding the nature, purpose, and risks of the research. Then, they were given the opportunity to ask questions regarding the research. Demographic data, medical history, and sports history of the subjects were collected using a questionnaire. Next, the anatomical and anthropometric variables were measured. Accordingly, upon introducing and describing the TJA tests, the subjects performed 10 minutes of warm-up, and TJA data were recorded. Table 1 provides the study subject' demographic characteristics. All study participants were healthy and without prior tuck jump training. All measurements were conducted in Physical Education and Sports Science Research Laboratory of the University of Kurdistan. All study participants signed an informed consent approved by the Academic Committee Ethics in Biomedical Research of the University of Kurdistan before participating in the study.

A week before conducting the TJA test, the study subjects were familiarized with the testing procedure and anatomical and anthropometric variables were measured. A video presentation consisting of representative images from sagittal and frontal views of a TJA was played. Then, a live demonstration of correct tuck jump technique was presented to the samples. The TJA test consists of a 10-second continuous maximal height tuck jump with maximal effort level $[13,15]$. The study subjects were instructed to place their feet in the middle of the rectangle marked on the floor consisting of 4 smaller rectangles (Figure 1). 


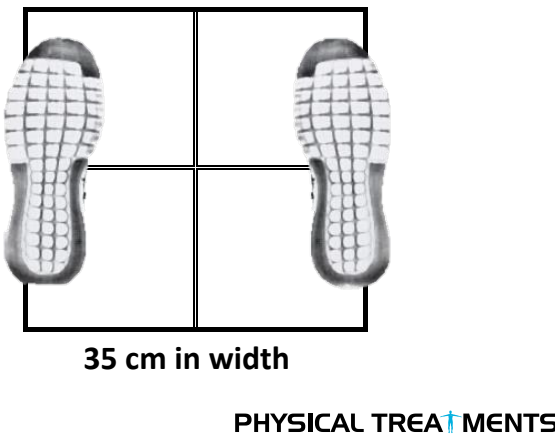

Figure 1. Rectangles marked on the floor TJA test

Initial set up for the TJA required 2 two-dimensional video cameras (Casio Japan, model CASIO-Ex-ZR1000, with the ability to shoot 1000 frames per second) on tripods to provide the sagittal and frontal views of the participants in the height marked at the athletes' waist. The camera was aligned three meters away in the sagittal plane and frontal plane.

The TJA test was performed using instructions from previous studies [16-19]. Necessary instructions were provided to the samples about how to perform the TJA test. Such information included lifting knees up as high as possible so both thighs were parallel with the ground, attempting to landing softly in the same footprint in each jump with their feet shoulder-width apart, and then immediately begin the next jump. Then, the study subjects were allowed to perform 3-5 practice trials to ensure the accurate performance of the TJA test. The study subjects performed a 10-minute neuromuscular warm-up in the testing session. This warm-up consisted of multidirectional movements, strength and dynamic stretching, the change of directions, jumps, and acceleration/deceleration movements.

Prior to data collection, all study subjects were allowed to perform no more than two TJA trials. After warm-up, each subject performed 10 seconds of continuous tuck jumps on the designated location. While performing TJA test, no feedback was provided to the study subjects; after 10 seconds, the jumping and cameras recording stopped.

Each study subject's recorded TJA performance was independently scored across 10 criteria. Table 2 and Figure 2 present the individual scoring criteria for each item of the modified TJA. Table 3 demonstrates the categorization of neuromuscular deficiencies based on these 10 items. The films recorded by two cameras (sagittal and frontal views) were evaluated using the free video software (Kinovea). Kinovea allowed videos to be played at various speeds and frame-by-frame; also, the two cameras were synchronized. Scoring TJA performance by advancing the videos was conducted on a frame by frame basis. If the study subjects met the criteria, score zero was assigned and if subjects failed to meet the criteria scores one or two were given. In the original TJA test, a lower score indicates a better performance. The researcher was allowed to independently watch the videos as many times as necessary and at whatever speeds required to score each test. Then, the statistical analysis of the data was performed (the scores of the 10 items)

The obtained data were analyzed in SPSS at a significance level of 0.5 . Descriptive statistics were performed on all data, e.g. the frequency and percentage of neuromuscular deficiencies (Figure $3 \&$ Table 4). The Mean \pm SD scores of all variables were calculated (Table 4). The outcome measurements of tuck-jump deficits were scored by the researcher in both gender groups. The 10 criteria were analyzed for each subject from frontal and sagittal video views. We ensured the homogeneity of variance by Levene's test (Table 4) and the normal distribution of data by Shapiro-Wilk test. To determine the differences between the mean values of tuck jump in male and female athletes and to examine the effects of the groups, one-way Analysis of Variance (ANOVA) was used (Table 4).

\section{Results}

Descriptive data analysis results suggested that ligament dominance is most common neuromuscular deficiencies $(64.4 \%)$, and $>50 \%$ of the subjects had the leg dominance and trunk dominance $(53.8 \%)$; however, the prevalence of neuromuscular fatigue $(9.2 \%)$ and quadriceps dominance (15.2\%) was small. One-way ANOVA results revealed a significant difference between the tuck jump score in male and female athletes $(\mathrm{P}<0.01)$. The gender difference was not significant in neuromuscular fatigue and quadriceps dominance. However, there was a significant gender-wise difference in ligament dominance, trunk dominance, and leg dominance $(\mathrm{P}<0.01)$. The prevalence of leg dominance in males $(65.5 \%)$ was higher than that of females $(45.5 \%)$. However, the prevalence of ligament dominance in female $(81.8 \%)$ was higher than that of males $(40 \%)$. Additionally, the prevalence of trunk dominance in females $(72 \%)$ was higher than that of males $(26.3 \%)$. In both groups, the prevalence of neuromuscular fatigue and quadriceps dominance was $<16 \%$. 
Table 1. Scoring criteria for each item of the Modified TJA

\begin{tabular}{|c|c|c|c|c|c|}
\hline $\begin{array}{l}\text { Phase } \\
\text { of Jump }\end{array}$ & Criterion & View & None (0) & Small (1) & Large (2) \\
\hline \multirow{3}{*}{ 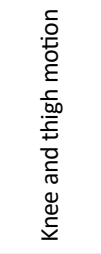 } & $\begin{array}{l}\text { 1. Lower extremity } \\
\text { valgus at landing }\end{array}$ & Frontal (F) & No valgus & Slight valgus & Obvious valgus: both knees touch \\
\hline & $\begin{array}{l}\text { 2. Thighs failed to reach } \\
\text { parallel (the peak of } \\
\text { jump) }\end{array}$ & Lateral (L) & $\begin{array}{c}\text { The knees are higher } \\
\text { or at the same level } \\
\text { as the hips }\end{array}$ & $\begin{array}{l}\text { The middle of the knees } \\
\text { are at a lower level than } \\
\text { the middle of the hips }\end{array}$ & $\begin{array}{l}\text { The whole knees are under the } \\
\text { entire hips }\end{array}$ \\
\hline & $\begin{array}{l}\text { 3. Thighs are unequal } \\
\text { in terms of side-to-side } \\
\text { during flight }\end{array}$ & $\mathrm{F}$ & $\begin{array}{l}\text { Thighs equal side- } \\
\text { to-side }\end{array}$ & $\begin{array}{l}\text { Thighs slightly unequal } \\
\text { side-to-side }\end{array}$ & $\begin{array}{l}\text { Thighs completely unequal side-to-side } \\
\text { (one knee is over the other) }\end{array}$ \\
\hline \multirow{4}{*}{ 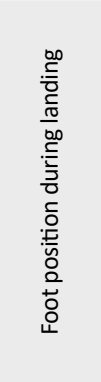 } & $\begin{array}{l}\text { 4. Foot placement } \\
\text { without shoulder-width } \\
\text { apart }\end{array}$ & $\mathrm{F}$ & $\begin{array}{l}\text { Foot placement with } \\
\text { exactly shoulder- } \\
\text { width apart }\end{array}$ & $\begin{array}{l}\text { Foot placement mostly } \\
\text { shoulder-width apart }\end{array}$ & $\begin{array}{l}\text { Both feet entirely together and } \\
\text { touch at landing }\end{array}$ \\
\hline & $\begin{array}{l}\text { 5. Foot placement is not } \\
\text { parallel } \\
\text { (front to back) }\end{array}$ & $\mathrm{L}$ & $\begin{array}{l}\text { Foot (the end of the } \\
\text { feet) placement is } \\
\text { parallel }\end{array}$ & $\begin{array}{l}\text { Foot placement mostly } \\
\text { parallel }\end{array}$ & $\begin{array}{l}\text { Foot placement unparalleled (one foot } \\
\text { is over half the distance of the other } \\
\text { foot/leg) }\end{array}$ \\
\hline & $\begin{array}{l}\text { 6. Foot contact timing is } \\
\text { unequal }\end{array}$ & $\mathrm{F}$ & $\begin{array}{l}\text { Foot contact timing } \\
\text { equal side-to-side }\end{array}$ & $\begin{array}{l}\text { Foot contact timing } \\
\text { slightly unequal }\end{array}$ & $\begin{array}{l}\text { Foot contact timing completely } \\
\text { unequal }\end{array}$ \\
\hline & $\begin{array}{l}\text { 7. Excessive landing } \\
\text { contact noise }\end{array}$ & $\mathrm{F} / \mathrm{L}$ & $\begin{array}{l}\text { Subtle noise at land- } \\
\text { ing (landing on the } \\
\text { balls of } \\
\text { their feet) }\end{array}$ & $\begin{array}{l}\text { Audible noise at landing } \\
\text { (heels almost touch the } \\
\text { ground at landing) }\end{array}$ & $\begin{array}{l}\text { Loud and pronounced noise at } \\
\text { landing (the contact of the entire } \\
\text { foot and heel on the ground } \\
\text { between jumps) }\end{array}$ \\
\hline \multirow{3}{*}{ 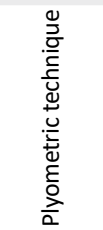 } & 8. Pause between jumps & $\mathrm{F} / \mathrm{L}$ & $\begin{array}{l}\text { Reactive and reflex } \\
\text { jumps }\end{array}$ & $\begin{array}{l}\text { Small pause between } \\
\text { jumps }\end{array}$ & $\begin{array}{l}\text { Considerable pause between jumps (or } \\
\text { double contact between jumps) }\end{array}$ \\
\hline & $\begin{array}{l}\text { 9. Technique declines } \\
\text { prior to } 10 \text { seconds }\end{array}$ & $\mathrm{F} / \mathrm{L}$ & $\begin{array}{l}\text { No decline in tech- } \\
\text { nique }\end{array}$ & $\begin{array}{l}\text { Technique declines after } \\
5 \text { seconds }\end{array}$ & Technique declines before 5 seconds \\
\hline & $\begin{array}{l}\text { 10. Fails to land in the } \\
\text { same footprint }\end{array}$ & $\mathrm{F} / \mathrm{L}$ & $\begin{array}{l}\text { Lands in the same } \\
\text { footprint }\end{array}$ & $\begin{array}{l}\text { Fails to land in the same } \\
\text { footprint, but it is inside } \\
\text { the shape }\end{array}$ & Lands outside the shape \\
\hline
\end{tabular}

\section{Discussion}

The present study investigated the prevalence of neuromuscular deficits in female and male collegiate athletes during a 10 -second tuck jump with a modified scoring system (0-2). The higher TJA scores indicated weakened neuromuscular control and high-risk movement patterns; these are associated with an increased risk of lower extremity injury [5]. The modified TJA is a user-friendly clinical option that requires minimal equipment, takes only minutes to administer, and could help to detect reductions high-risk movement patterns after a prevention exercise program [13]. Furthermore, modified TJA has excellent between-session and good inter-rater reliability for its total score $[12,13]$. Therefore, the achieved results could be beneficial for coaches and clinicians

Table 2. The categorization of neuromuscular deficiencies based on the 10 items of the Modified TJA

\begin{tabular}{|c|c|c|}
\hline Neuromuscular Deficiencies & Description & Technique Flaws \\
\hline Ligament dominance & $\begin{array}{l}\text { Imbalance between the neuromuscular and ligamentous } \\
\text { control of the dynamic knee stability }\end{array}$ & $\begin{array}{l}\text { Lower extremity valgus at landing } \\
\text { Foot placement without shoulder-width apart }\end{array}$ \\
\hline Quadriceps dominance & $\begin{array}{l}\text { Imbalance between knee extensor and flexor strength, } \\
\text { recruitment, and coordination }\end{array}$ & Excessive landing contact noise \\
\hline \multirow[t]{2}{*}{$\begin{array}{l}\text { Leg dominance or residual } \\
\text { injury deficits }\end{array}$} & $\begin{array}{l}\text { Imbalance between the } 2 \text { lower extremities in strength, } \\
\text { coordination, and control }\end{array}$ & $\begin{array}{l}\text { Thighs not equal side-to-side (during flight) } \\
\text { Foot placement, not parallel (front to back) }\end{array}$ \\
\hline & & Foot contact timing unequal \\
\hline \multirow{3}{*}{$\begin{array}{l}\text { Trunk dominance or core } \\
\text { dysfunction }\end{array}$} & & Thighs do not reach parallel (peak of jump) \\
\hline & $\begin{array}{l}\text { Imbalance between the inertial demands of the trunk and } \\
\text { core control and coordination to resist it }\end{array}$ & Pause between jumps \\
\hline & & $\begin{array}{c}\text { Does not land in the same footprint (excessive in- } \\
\text { flight motion) }\end{array}$ \\
\hline Technique perfection & Not defined & Technique declines prior to $10 \mathrm{~s}$ \\
\hline
\end{tabular}




\begin{tabular}{|c|c|c|c|c|c|c|c|}
\hline \multirow{2}{*}{ } & \multicolumn{3}{|c|}{ Score } & \multirow{2}{*}{$\begin{array}{l}\frac{\pi}{2} \\
\stackrel{ \pm}{ \pm}\end{array}$} & \multicolumn{3}{|c|}{ Score } \\
\hline & 0 & 1 & 2 & & 0 & 1 & 2 \\
\hline
\end{tabular}
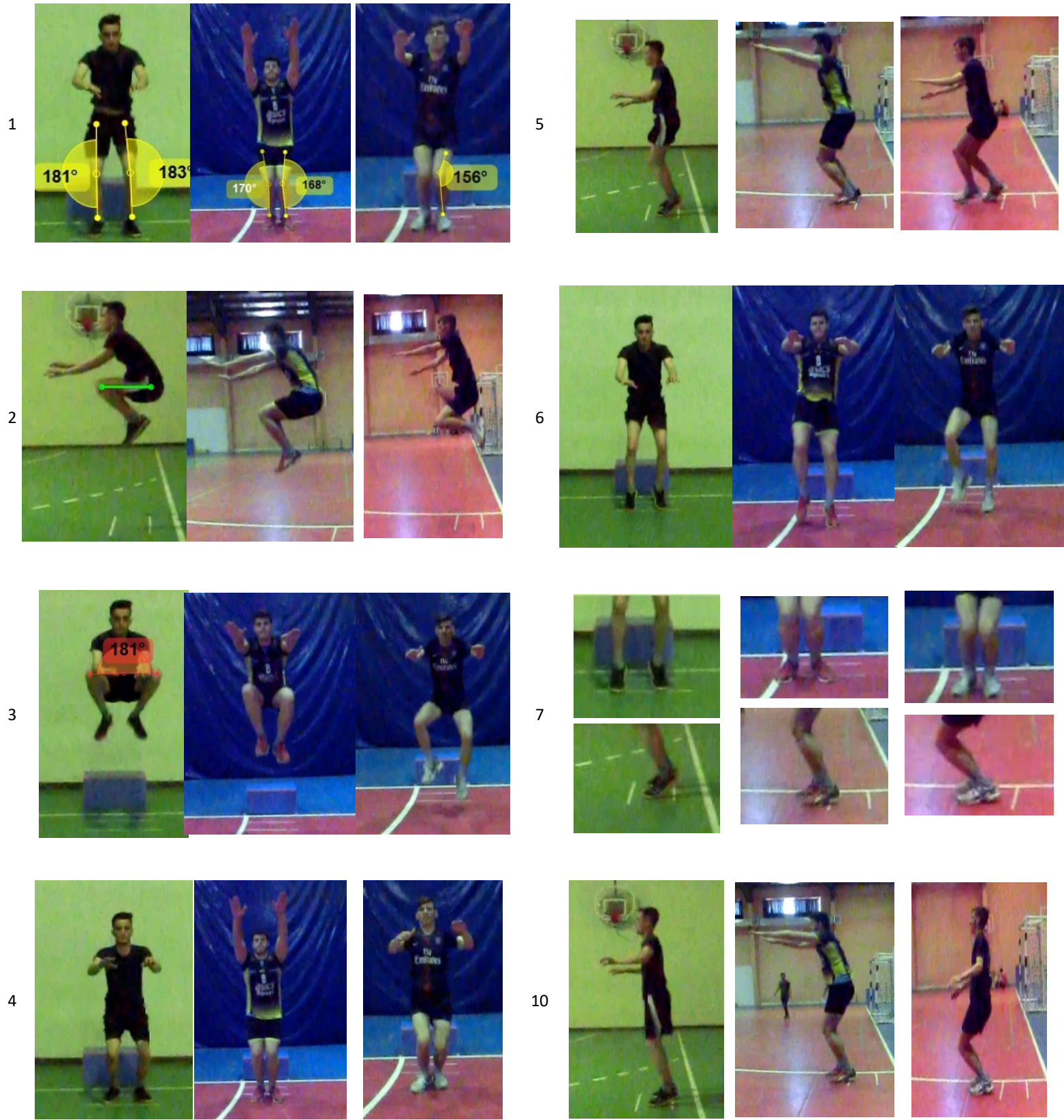

Figure 2. Scoring criteria for each item of the Modified TJA

PHYSICAL TREA $\|$ MENTS

as a prevention exercise program. It could be used for injury prevention to target deficits associated with ACL injury risk in male and female athletics, as well as the differences between them. The tested hypothesis was supported by the finding of the significant gender difference between the tuck jump score $(\mathrm{P}<0.01)$. In females, the prevalence of ligament dominance $(81.80 \%)$, trunk dominance $(72 \%)$, neuromuscular fatigue $(14.3 \%)$, and quadriceps $(20 \%)$ dominance was higher, compared to males. However, in males, only the prevalence of leg dominance $(65.5 \%)$ was higher than that of the females.

The ligament dominance is among the most essential mechanisms of non-contact ACL injury. Where muscles insufficiently absorb the ground reaction forces, knee ligaments must absorb this force and the knee collapses into dynamic knee valgus position, i.e., called ligament 
Table 3. Frequency and percentage of neuromuscular deficiencies in the study subjects

\begin{tabular}{|c|c|c|c|c|c|c|c|}
\hline \multirow{2}{*}{ Neuromuscular Deficiencies } & \multirow{2}{*}{ Grade } & \multicolumn{3}{|c|}{ No. } & \multicolumn{3}{|c|}{$\%$} \\
\hline & & All & Male & Female & All & Male & Female \\
\hline \multirow{3}{*}{ Ligament dominance } & 0 & 47 & 33 & 14 & 35.6 & 60.0 & 18.2 \\
\hline & 1 & 59 & 19 & 40 & 44.7 & 34.5 & 51.9 \\
\hline & 2 & 26 & 3 & 23 & 19.7 & 5.5 & 29.9 \\
\hline \multirow{3}{*}{ Quadriceps dominance } & 0 & 112 & 44 & 68 & 84.8 & 88.3 & 80.0 \\
\hline & 1 & 16 & 10 & 6 & 12.1 & 7.8 & 18.2 \\
\hline & 2 & 4 & 1 & 3 & 3.0 & 3.9 & 1.8 \\
\hline \multirow{3}{*}{ Neuromuscular fatigue } & 0 & 119 & 53 & 66 & 90.2 & 96.4 & 85.7 \\
\hline & 1 & 13 & 2 & 11 & 9.8 & 3.6 & 14.3 \\
\hline & 2 & 0 & 0 & 0 & 0 & 0 & 0 \\
\hline \multirow{3}{*}{$\begin{array}{c}\text { Leg } \\
\text { dominance }\end{array}$} & 0 & 61 & 19 & 42 & 46.2 & 34.5 & 54.5 \\
\hline & 1 & 58 & 27 & 31 & 43.9 & 49.1 & 40.3 \\
\hline & 2 & 13 & 9 & 4 & 9.8 & 16.4 & 5.2 \\
\hline \multirow{3}{*}{$\begin{array}{c}\text { Trunk } \\
\text { dominance }\end{array}$} & 0 & 61 & 40 & 21 & 46.2 & 72.7 & 27.3 \\
\hline & 1 & 58 & 14 & 44 & 43.9 & 25.5 & 57.1 \\
\hline & 2 & 13 & 1 & 12 & 9.8 & 1.8 & 15.6 \\
\hline
\end{tabular}

dominance [5]. High level of force sustained over a short period of time may result in ligament rupture; it is more frequent in females, than males [5]. Increased dynamic knee valgus (ligament dominance) during landing was also introduced as a critical risk factor for ACL injury $[5,20]$. The collected results also revealed that ligament dominance was the most common neuromuscular defect $(64.4 \%)$ during the TJA test in the subjects. More than $80 \%$ of females and $40 \%$ of males have the knee valgus; therefore, many studies have investigated the effect of interventional exercises on the reduction of knee valgus. Significant improvement in ligament dominance (knee valgus) has been reported in some of these studies [2124]; however, many other studies reported that the exercise interventions failed to improve knee valgus [25-27]. Most of these studies mainly focused on plyometric or balance interventional exercises; regardless of whether the subjects had or not had ligament dominance or other

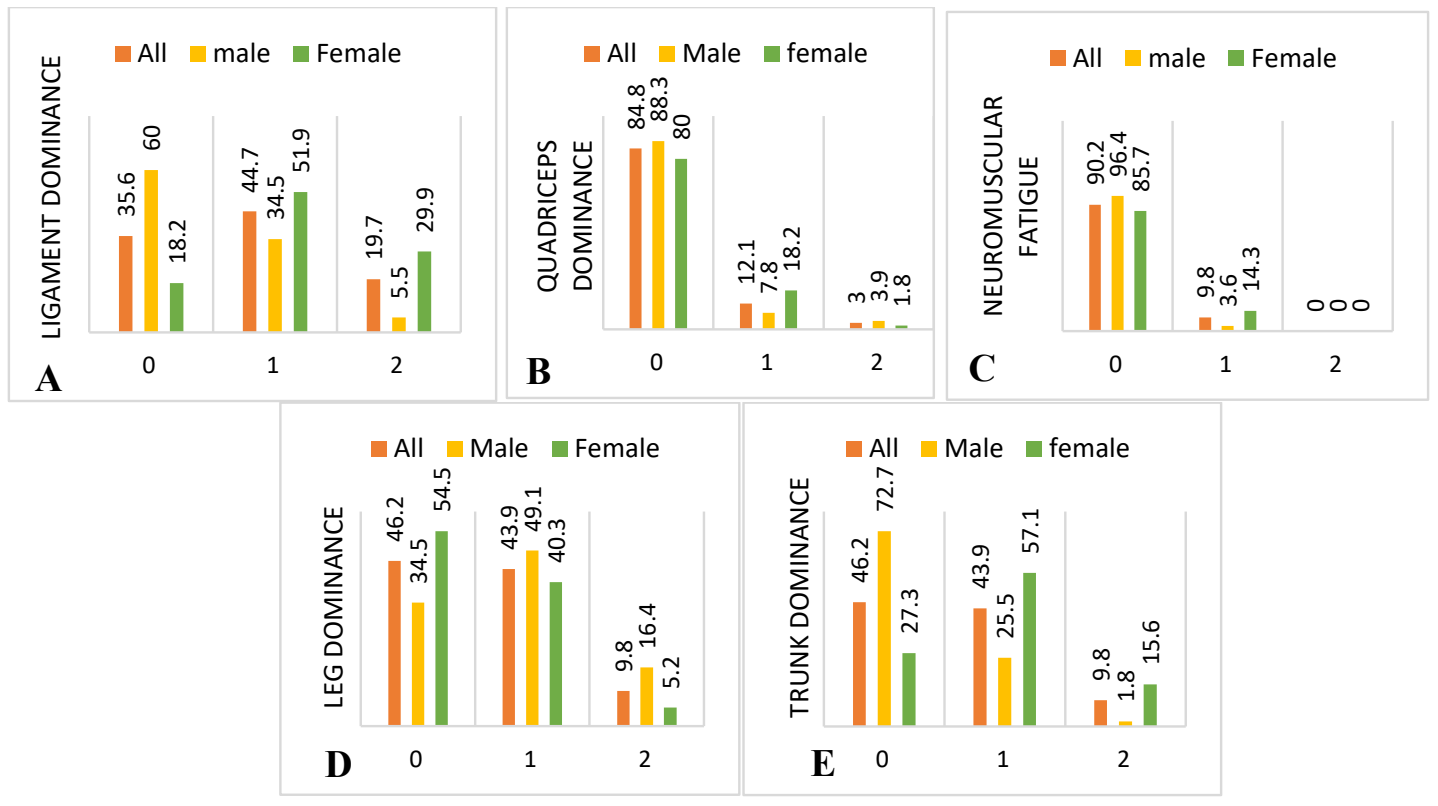

Figure 3. The percentage of neuromuscular deficiencies in female and male athletics

PHYSICAL TREA \MENTS

A. Ligament dominance; B. Quadriceps dominance; C. Neuromuscular fatigue; D. Leg dominance; E. and Trunk dominance 
Table 4. The Homogeneity of variance (Levene's test) and effects of groups (ANOVA)

\begin{tabular}{|c|c|c|c|c|}
\hline \multirow{2}{*}{ Variables } & \multicolumn{2}{|c|}{ Homogeneity of Variances } & \multicolumn{2}{|c|}{ ANOVA } \\
\hline & Sig. & Levene's Test & df & Sig. \\
\hline TJA & 0.63 & 0.23 & 131 & 0.01 \\
\hline Ligament dominance & 0.78 & 0.08 & 131 & 0.01 \\
\hline Quadriceps dominance & 0.22 & 1.51 & 131 & 0.44 \\
\hline Neuromuscular fatigue & 0.22 & 1.52 & 131 & 0.54 \\
\hline Leg dominance & 0.81 & 0.05 & 131 & 0.01 \\
\hline Trunk dominance & 0.37 & 0.81 & 131 & 0.01 \\
\hline
\end{tabular}

neuromuscular impairments, like trunk dominance, the interventional exercise program was applied. Females usually have a higher rate of ACL injury than males (8.9), and $76.6 \%$ of ACL injuries resulted in surgical treatment [28]. Therefore, considering the neuromuscular impairment gender-wise differences in prevention exercise programs is vital. The achieved results suggested that to prevent ACL injury, correction ligament dominance and correction trunk dominance, as well as leg dominance should be targeted in interventional exercise programs.

Moreover, interventional exercise programs for females should focus on the ligament dominance, trunk dominance, and leg dominance, respectively; however, for males, leg dominance should be the top priority. In addition, ACL injury is among the most devastating injuries requiring surgical treatment and extensive rehabilitation. It also has a potential for long-term health problems, like osteoarthritis and is not limited to female athletes [28]. Participation in sports will always be associated with a specific level of ACL injury in both genders. Thus, preventing this injury is necessary for both genders. As a result, both groups were examined in this study.

The trunk dominance occurs when athletes fail to adequately feel their trunk position in a 3-dimensional plan, and allow greater movement following a perturbation of their trunk; therefore, athletes are unable to precisely control the trunk [5]. Previous studies reported that impaired core stability is a risk factor for the development of lower extremity injuries [29]. For example, reduced core strength is predictive for ACL injuries [30], increased lateral trunk displacement is the strongest predictor of knee injuries [30], and impaired proprioception of the core predicts knee injury risk [30]. Trunk displacement predicted knee ligament injury with $91 \%$ sensitivity and $68 \%$ specificity and is higher in athletes with ACL in- juries than the uninjured ones [31]. Although trunk displacements predicted ACL injury risk in female athletes with $89 \%$ and $91 \%$ accuracy, only a history of low back pain was a significant predictor of knee ligament injury risk in male athletes [31]. The collected results indicated that trunk dominance was among the most common neuromuscular deficits $(53.8 \%)$ during the TJA test, especially in female athletes. This is probably because $>70$ of the females have trunk dominance, while only $27.3 \%$ of the males have it.

In tasks such as landing that typically requires side-toside symmetry of the lower extremities, athletes with leg dominance tend to be leaner on one-leg. Because there is a difference between limbs in muscle recruitment patterns, muscle strength, and muscle flexibility, athlete's limbs are asymmetric [5]. Female skiers usually demonstrated a 2-fold higher risk of suffering ACL ruptures of their non-dominant leg, compared to male skiers [32]. Non-contact ACL injury in soccer female athletes often occurs in the supporting leg (non-dominant); whereas it often occurs in the kicking leg (dominant) among the males [33]. In other words, in soccer, $74.1 \%$ of ACL injuries in males occurs on the dominant leg; however, $32 \%$ of ACL injury occurs on the dominant leg of females [33]. The study results suggested that leg dominance is among the most common neuromuscular deficits $(53.8 \%)$ during the TJA test, especially in male athletes because $>65 \%$ of the males had leg dominance, while only $45.5 \%$ of the females had that.

In female colligate athletes, the incidence of the ligament dominance is equal to $81.8 \%$; thus, trunk dominance is $72.7 \%$ and leg dominance is $45.5 \%$. Accordingly, it is recommended that ACL injury prevention exercise programs for females emphasize on the correction of ligament dominance and trunk dominance 
defects. However, for the male colligate athlete's, the correction of leg dominance deficiency followed by ligament dominance is a priority. That is because in male colligate athletes, the incidence of the leg dominance is $65.5 \%$, the ligament dominance is $40 \%$, and trunk dominance is $27.3 \%$.

\section{Conclusion}

The prevalence rate of neuromuscular deficits during tuck jump in female and male subjects revealed that $>50 \%$ of the study subjects had the ligament dominance $(64.4 \%)$, leg dominance $(53.8 \%)$, and trunk dominance $(53.8 \%)$. Thus, it is recommended that preventive exercise programs mainly emphasize on the correction of these defects. However, the correction of leg dominance deficiency is a priority for males; the correction of ligament dominance and trunk dominance is a priority for females.

\section{Ethical Considerations}

\section{Compliance with ethical guidelines}

All athletes read and signed a written informed consent before testing and provided a detailed injury history. The study participants were informed about the research purpose and its implementation stages; they were also assured about the confidentiality of their obtained information. Moreover, they were allowed to leave the study whenever they wished, and if desired, the research results would be available to them.

\section{Funding}

The authors received grant (Code: 97.11.22/907) from the University of Kurdistan.

\section{Authors' contributions}

Conceptualization, Methodology, Investigation, Resources, Data gathering, Writing - Original draft, Preparation, Project administration: Hemn Mohammadi; Statistical Analysis, and Editing: Saeed Ghaeeni.

\section{Conflict of interest}

The authors declared no conflict of interest.

\section{Acknowledgments}

The authors express their thanks to all of the undergraduate students in 2018-2019 academic year of Physical Education and Sports Science at the University of
Kurdistan. Thanks are also extended to the staff of in the same faculty in the University of Kurdistan, Physical Education and Sports Science Research Laboratory of the University of Kurdistan and all others who contributed to this study.

\section{References}

[1] Kay MC, Register-Mihalik JK, Gray AD, Djoko A, Dompier TP, Kerr ZY. The Epidemiology of severe injuries sustained by national collegiate athletic association student-athletes, 2009-2010 through 2014-2015. Journal of Athletic Training. 2017; 52(2):11728. [DOI:10.4085/1062-6050-52.1.01] [PMID] [PMCID]

[2] Stanley LE, Kerr ZY, Dompier TP, Padua DA. Sex differences in the incidence of anterior cruciate ligament, medial collateral ligament, and meniscal injuries in collegiate and high school sports: 2009-2010 through 2013-2014. American Journal of Sports Medicine. 2016; 44(6):1565-72. [DOI:10.1177/0363546516630927] [PMID]

[3] Rosa BB, Asperti AM, Helito CP, Demange MK, Fernandes TL, Hernandez AJ. Epidemiology of sports injuries on collegiate athletes at a single center. Acta Ortopedica Brasileira. 2014; 22(6):321-4. https://doi.org/10.1590/1413-785220192706222834 [DOI:10.1590/1413-78522014220601007]

[4] Stewart BA, Momaya AM, Silverstein MD, Lintner D. The costeffectiveness of anterior cruciate ligament reconstruction in competitive athletes. American Journal of Sports Medicine. 2017; 45(1):23-33. [DOI:10.1177/0363546516664719] [PMID]

[5] Hewett TE, Ford KR, Hoogenboom BJ, Myer GD. Understanding and prevention ACL injuries: Current biomechanical and epidemiological consideration. North American Journal of Sports Physical Therapy. 2010; 5(4):234-51

[6] Mohammadi H, Daneshmandi H, Alizadeh MH, Shamsimajlan A. [Screening tests for neuromuscular imbalance that affecting the non-contact ACL injury (Persian)]. Scientific Journal of Kurdistan University of Medical Sciences. 2015; 20(2):85-105.

[7] Mohammadi H, Daneshmandi H, Alizadeh MH, Shamsimajlan A. [The Effect of ACL Intervention Programs on the Improvement of Neuromuscular Deficiencies and Reducing the Incidence of ACL Injury (Persian)]. Journal of Rehabilitation Medicine. 2015; 4(2):159-69.

[8] Myer GD, Ford KR, Di Stasi SL, Foss KD, Micheli LJ, Hewett TE. High knee abduction moments are common risk factors for Patellofemoral Pain (PFP) and Anterior Cruciate Ligament (ACL) injury in girls: Is PFP itself a predictor for subsequent ACL injury? British Journal of Sports Medicine. 2015; 49(2):118-22. [DOI:10.1136/ bjsports-2013-092536] [PMID] [PMCID]

[9] Kilic O, Maas M, Verhagen E, Zwerver J, Gouttebarge V. Incidence, aetiology, and prevention of musculoskeletal injuries in volleyball: A systematic review of the literature. European Journal of Sport Science. 2017; 17(6):765-93. [DOI:10.1080/17461391. 2017.1306114] [PMID]

[10] Padua DA, DiStefano LJ, Beutler AI, de la Motte SJ, DiStefano MJ, Marshall SW. The landing error scoring system as a screening tool for an anterior cruciate ligament injury-prevention pro- 
gram in elite-youth soccer athletes. Journal of Athletic Training. 2015; 50(6):589-95. [DOI:10.4085/1062-6050-50.1.10] [PMID] [PMCID]

[11] Myer GD, Ford KR, Khoury J, Succop P, Hewett TE. Development and validation of a clinic-based prediction tool to identify female athletes at high risk for anterior cruciate ligament injury. American Journal of Sports Medicine. 2010; 38(10):2025-33. [DOI:10.1177/0363546510370933] [PMID] [PMCID]

[12] Gokeler A, Dingenen B. Between-session and inter-rater reliability of the modified tuck jump assessment in healthy adult athletes. Physical Therapy in Sport. 2019; 37:10-4. [DOI:10.1016/j. ptsp.2019.02.002] [PMID]

[13] Fort-Vanmeerhaeghe A, Montalvo AM, Lloyd RS, Read P, Myer GD. Intra- and inter-rater reliability of the modified tuck jump assessment. Journal of Sports Science and Medicine. 2017 16(1):117-24. [PMID] [PMCID]

[14] Fort-Vanmeerhaeghe A, Benet A, Mirada S, Montalvo AM, Myer GD. Sex and maturation differences in performance of functional jumping and landing deficits in youth athletes. Journal of Sport Rehabilitation. 2019; 28(6):606-13. [DOI: 10.1123/ jsr.2017-0292] [PMID]

[15] Stroube BW, Myer GD, Brent JL, Ford KR, Heidt RS Jr, Hewett TE. Effects of task specific augmented feedback on deficit modification during performance of the tuck jump exercise. Journal of Sport Rehabilitation. 2013; 22(1):7-18. [DOI:10.1123/jsr.22.1.7] [PMID]

[16] Hoog P, Warren M, Smith CA, Chimera NJ. Functional hop and tuck jump assessment female division I collegiate athletes participating in high versus low ACL injury prone sports: A cross sectional analysis. International Journal of Sports Physical Therapy. 2016; 11(6):945-53. [PMID] [PMCID]

[17] Lininger MR, Smith CA, Chimera NJ, Hoog P, Warren M. Tuck jump assessment: An exploratory factor analysis in a college age population. The Journal of Strength and Conditioning Research 2017; 31(3):653-9. [DOI:10.1519/JSC.0000000000001186] [PMID]

[18] Smith CA, Olson BK, Olson LA, Chimera NJ, Warren M. Comparison of female collegiate athletes and college age cohort in tuck jump assessment. The Journal of Strength and Conditioning Research. 2017; 31(4):1048-54. [DOI:10.1519/ JSC.0000000000001573] [PMID]

[19] Read PJ, Oliver JL, de Ste Croix MB, Myer GD, Lloyd RS. Reliability of the tuck jump injury risk screening assessment in elite male youth soccer players. The Journal of Strength and Conditioning Research. 2016; 30(6):1510-6. [DOI:10.1519/ JSC.0000000000001260] [PMID] [PMCID]

[20] Mohammadi H, Daneshmandi H, Alizadeh M. [The effect of dynamic knee valgus during overhead squat on distal and proximal knee joints muscle strength and range of motion in basketball player (Persian)]. Journal of Sport Biomechanics. 2018;3(4):17-27.

[21] Herrington L. The effects of 4 weeks of jump training on landing knee valgus and crossover hop performance in female basketball players. Journal of Strength and Conditioning Research. 2010; 24(14):3427-32. [DOI:10.1519/JSC.0b013e3181c1fcd8] [PMID]

[22] Noyes FR, Barber-Westin SD, Smith ST, Campbell T, Garrison TT. A training program to improve neuromuscular and performance indices in female high school basketball players. Journal of Strength and Conditioning Research. 2012; 26(3):709-19. [DOI:10.1519/JSC.0b013e318228194c] [PMID]
[23] Noyes FR, Barber-Westin SD, Tutalo Smith ST, Campbell T. A training program to improve neuromuscular and performance indices in female high school soccer players. Journal of Strength and Conditioning Research. 2013; 27(2):340-51. [DOI:10.1519/ JSC.0b013e31825423d9] [PMID]

[24] Mohammadi H, Daneshmandi H, Alizadeh MH. The effect of correction medial knee displacement during drop vertical jump on performance in male basketball athletes. Physical Treatments. 2019; 9(1):1-14. [DOI:10.32598/PTJ.9.1.1]

[25] Chappell JD, Limpisvasti O. Effect of a neuromuscular training program on the kinetics and kinematics of jumping tasks. American Journal of Sports Medicine. 2008; 36(6):1081-6. [DOI:10.1177/0363546508314425] [PMID]

[26] Herman DC, Weinhold PS, Guskiewicz KM, Garrett WE, Yu B, Padua DA. The effects of strength training on the lower extremity biomechanics of female recreational athletes during a stopjump task. American Journal of Sports Medicine. 2008;36(4):73340. [DOI:10.1177/0363546507311602] [PMID]

[27] Herman DC, Oñate JA, Weinhold PS, Guskiewicz KM, Garrett WE, Yu B, et al. The effects of feedback with and without strength training on lower extremity biomechanics. American Journal of Sports Medicine. 2009; 37(7):1301-8. [DOI:10.1177/0363546509332253] [PMID]

[28] Joseph AM, Collins CL, Henke NM, Yard EE, Fields SK, Comstock RD. A multisport epidemiologic comparison of anterior cruciate ligament injuries in high school athletics. Journal of Athletic Training. 2013; 48(6):810-7. [DOI:10.4085/1062-605048.6.03] [PMID] [PMCID]

[29] De Blaiser C, De Ridder R, Willems T, Vanden Bossche L, Danneels $\mathrm{L}$, Roosen P. Impaired core stability as a risk factor for the development of lower extremity overuse injuries: A prospective cohort study. American Journal of Sports Medicine. 2019; 47(7):1713-21. [DOI:10.1177/0363546519837724] [PMID]

[30] De Blaiser C, Roosen P, Willems T, Danneels L, Bossche LV, De Ridder $\mathrm{R}$. Is core stability a risk factor for lower extremity injuries in an athletic population? A systematic review. Physical Therapy in Sport. 2018; 30:48-56. [DOI:10.1016/j.ptsp.2017.08.076] [PMID]

[31] Zazulak BT, Hewett TE, Reeves NP, Goldberg B, Cholewicki J. Deficits in neuromuscular control of the trunk predict knee injury risk: A prospective biomechanical-epidemiologic study. American Journal of Sports Medicine. 2007; 35(7):1123-30. [DOI:10.1177/0363546507301585] [PMID]

[32] Ruedl G1, Webhofer M, Helle K, Strobl M, Schranz A, Fink C, et al. Leg dominance is a risk factor for noncontact anterior cruciate ligament injuries in female recreational skiers. American Journal of Sports Medicine. 2012; 40(6):1269-73. [DOI:10.1177/0363546512439027] [PMID]

[33] Brophy R, Silvers HJ, Gonzales T, Mandelbaum BR. Gender influences: The role of leg dominance in ACL injury among soccer players. British Journal of Sports Medicine. 2010; 44(10):694-7. [DOI:10.1136/bjsm.2008.051243] [PMID] 